\title{
Performance Analysis of PV Energy System in Western Region of Saudi Arabia
}

\author{
Makbul Anwari ${ }^{1}$, Ayong Hiendro ${ }^{2}$ \\ ${ }^{1}$ Electrical Engineering Department, Umm Al-Qura University, Makkah, Saudi Arabia \\ ${ }^{2}$ Department of Electrical Engineering, Universitas Tanjungpura, Pontianak, Indonesia \\ Email: mmanwari@uqu.edu.sa, ayongh2000@yahoo.com
}

Received 2013

\begin{abstract}
The potential implementation of photovoltaic (PV) energy system in western region of Saudi Arabia was analyzed in this paper. HOMER (hybrid optimization model for electric renewable) software was used to perform the technical feasibility of the system. The feasibility of PV energy system was analyzed based on solar irradiances. Stand-alone PV systems with battery storage element will be evaluated and discussed. The analysis will be addressed to the impact of PV and battery storage on electric energy production.
\end{abstract}

Keywords: Stand-Alone PV System; Electric Energy Production; HOMER Software

\section{Introduction}

The Kingdom of Saudi Arabia is blessed with an abundance of energy resources. It has the world's largest proven oil reserves, the world's fourth largest proven gas reserves, has abundant wind and solar renewable energy resources, and is the world's 20th largest producer and consumer of electricity. Saudi Arabia makes negligible use of its renewable energy resources and almost all its electricity is produced from the combustion of fossil fuels [1].

Remarkable diversifications in terms of energy sources and the intensification of deploying renewable energy options are evident around the world. A set of renewable energy scenarios for the currently oil-rich Kingdom of Saudi Arabia has been presented to examine the prospects of renewable sources from the perspective of major oil producers. The drive towards renewable energy in Saudi Arabia should not be regarded as being a luxury but rather a must, as a sign of good governance, concern for the environment and prudence in oil-production policy $[2,3]$.

Electrical energy consumption in Saudi Arabia increased sharply during the last two decades due to rapid economic development and the absence of energy conservation measures. Peak loads reached nearly $24 \mathrm{GW}$ in 2001-25 times their 1975 level—and are expected to approach $60 \mathrm{GW}$ by 2023 . The total investment needed to meet this demand may exceed $\$ 90$ billion. Consequently, there is an urgent need to develop energy conservation policies for sustainable development [4].
Solar energy is one of the in-exhaustible, site-de- pendent, benign (does not produce emissions that contribute to the greenhouse effect), and potential source of renewable energy options that is being pursued by a number of countries with monthly average daily solar radiation in the range of 3-6 $\mathrm{kWh} / \mathrm{m}^{2}$, in an effort to reduce their dependence on fossil-based nonrenewable fuels [5].

The objective of this study is to assess the technical feasibility of the stand-alone PV energy system to meet the 2.5\%-load requirements of Makkah city with annual electrical energy demand of 71,500 MWh/yr.

\section{Load Profiles}

The load demand in the western region of Saudi Arabia varies monthly. The demand is the highest in August, while it is the lowest in January as shown in Figure 1. A random variability factor of $15 \%$ for day-to-day and $10 \%$ for time-step-to-time-step is given to HOMER software to cater for differences which may occur each day in load profile and the energy demand requirement for a year was generated automatically by HOMER software. The monthly load profile used for HOMER simulation is shown in Figure 2.

\section{Solar Radiation}

The clearness index and/or the solar radiation data can be used to represent the solar resource input. This data can be generated using HOMER software by entering the location data (i.e. the latitude and longitude). The latitude and longitude of Makkah are $21^{\circ} 26^{\prime}$ North and 39 $49^{\prime}$ 
East respectively. The solar radiation ranges between $4.15 \mathrm{kWh} / \mathrm{m}^{2} /$ day and $7.17 \mathrm{kWh} / \mathrm{m}^{2} /$ day. The scaled annual average of the solar radiation is estimated to be $5.94 \mathrm{kWh} / \mathrm{m}^{2} /$ day. It is noticed that solar irradiance is high (above the average) from March to September with a peak for the month of June, while solar irradiance is low for January, February, October, November and December. Figure 3 shows the solar radiation data inputs as used in HOMER software, on the right axis of which is the clearness index of the solar radiation.

\section{Design Specification}

In this simulation, the stand-alone PV energy system is considered at the three system-components, specifically, PV modules, storage batteries and inverters to supply to the AC load. In order to meet the user AC load profile as discussed previously, the following design specifications for each of the component are provided in Figure 4.
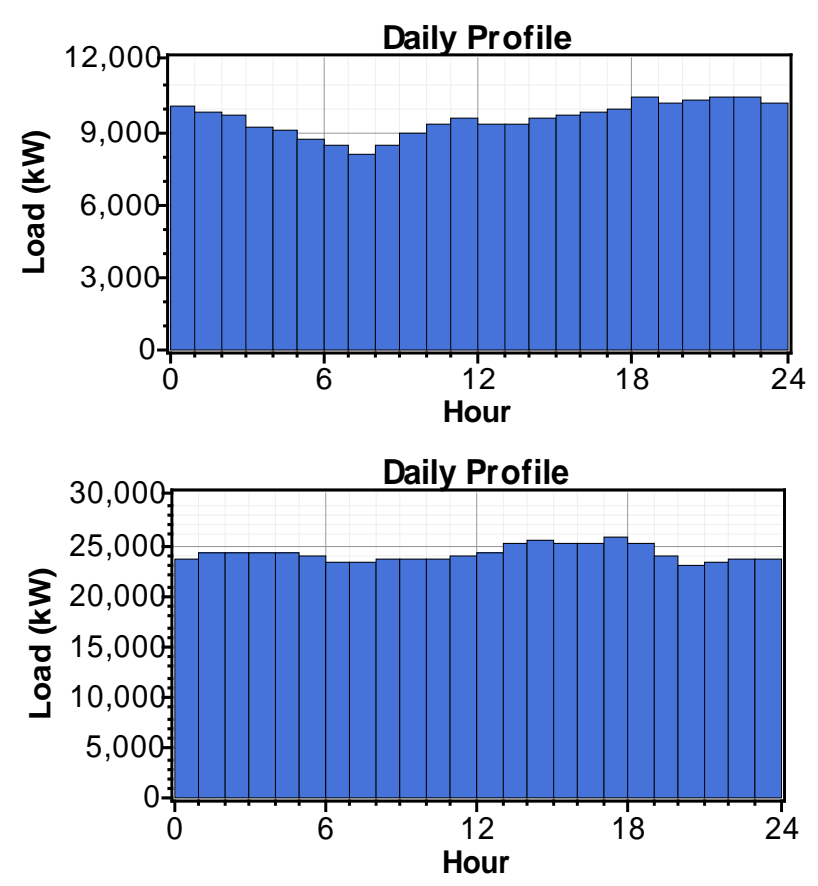

Figure 1. Daily load profiles (upper: January, lower: August).

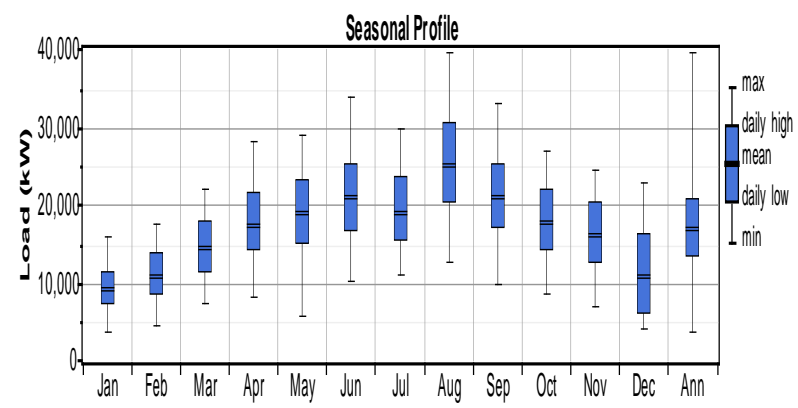

Figure 2. Monthly load profile of Makkah.

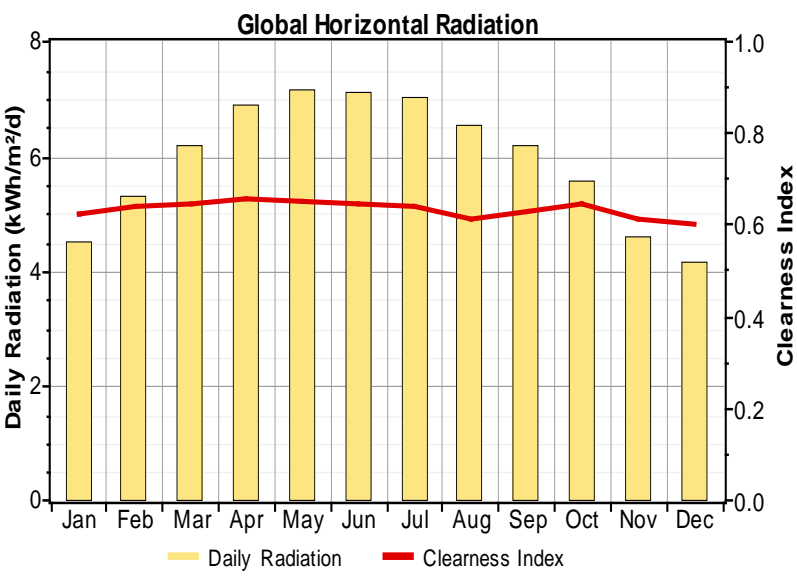

Figure 3. Solar radiation data.

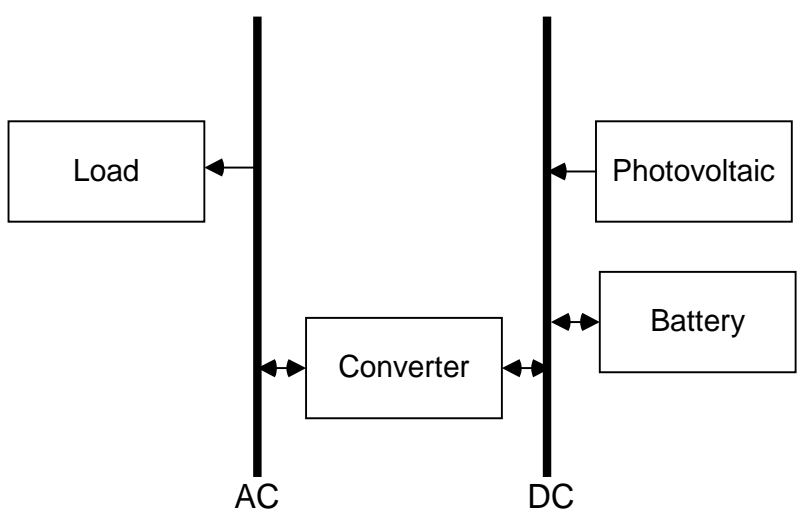

Figure 4. Design specification.

\subsection{PV Modules}

Solar energy is used as the base-load power source. In an isolated system, the renewable energy contribution of $50 \%$ is considered to be high. Such a system might be very difficult to control while maintaining a stable voltage and frequency. The level of renewable energy penetration in hybrid systems (deployed around the world) is generally in the range of $11 \%-25 \%$ [6].

The designed PV array size was $85 \mathrm{MW}$. This amount will be used to cater for the variety load demand in a year. The excess power generated will be used to charge the battery.

It should be highlighted that this PV array will only generate electricity at day time, from 6 a.m. to 6 p.m. At night, there is no electricity generated. Therefore, the output from solar would be $0 \mathrm{~W}$. At night, the battery will take over the task.

\subsection{Storage Battery}

The From the datasheet given by HOMER software, the minimum state of charge of the battery is $40 \%$. Its round trip efficiency is $80 \%$. The battery's replacement cost 
was assumed to be the same as the capital cost.

The battery chosen for this study is Surrette 6CS25P. The number of batteries per string is set to one and the bus voltage is ignored. This approach is appropriate for preliminary sizing analysis to determine the optimal storage capacity.

\subsection{Inverter}

The inverter is chosen based on the selected PV modules. For $85 \mathrm{MW}$ rated output $\mathrm{PV}$, the inverter is rated at 85 MW to fully supply the power from PV. However, it is assumed that the inverter has an efficiency of $90 \%$. Therefore, the supplied power will be less than the rated power.

A brief summary on the data for each of the selected components is provided in Table 1.

\section{Simulation Results}

The monthly average PV production is presented in Figure 5. The total PV production in a year is 166,788 $\mathrm{MWh} / \mathrm{yr}$, while the AC primary load is 71,542 MWh/yr.
Tabel I. Data for Selected Components.

\begin{tabular}{ll}
\hline Description & Data \\
\hline PV & \\
Size & $85 \mathrm{MW}$ \\
Lifetime & $25 \mathrm{yr}$
\end{tabular}

$\begin{array}{ll}\text { Storage battery } & \\ \text { Type of battery } & \text { Surrette CS25P } \\ \text { Nominal voltage } & 6 \mathrm{~V} \\ \text { Nominal capacity } & 1156 \mathrm{Ah} \\ \text { Maximum capacity } & 1163 \mathrm{Ah} \\ \text { Minimum SOC } & 40 \% \\ \text { Lifetime } & 12 \mathrm{yr}\end{array}$

\begin{tabular}{ll} 
Inverter & \\
Size & $85 \mathrm{MW}$ \\
Lifetime & $15 \mathrm{yr}$ \\
Efficiency & $90 \%$ \\
\hline
\end{tabular}

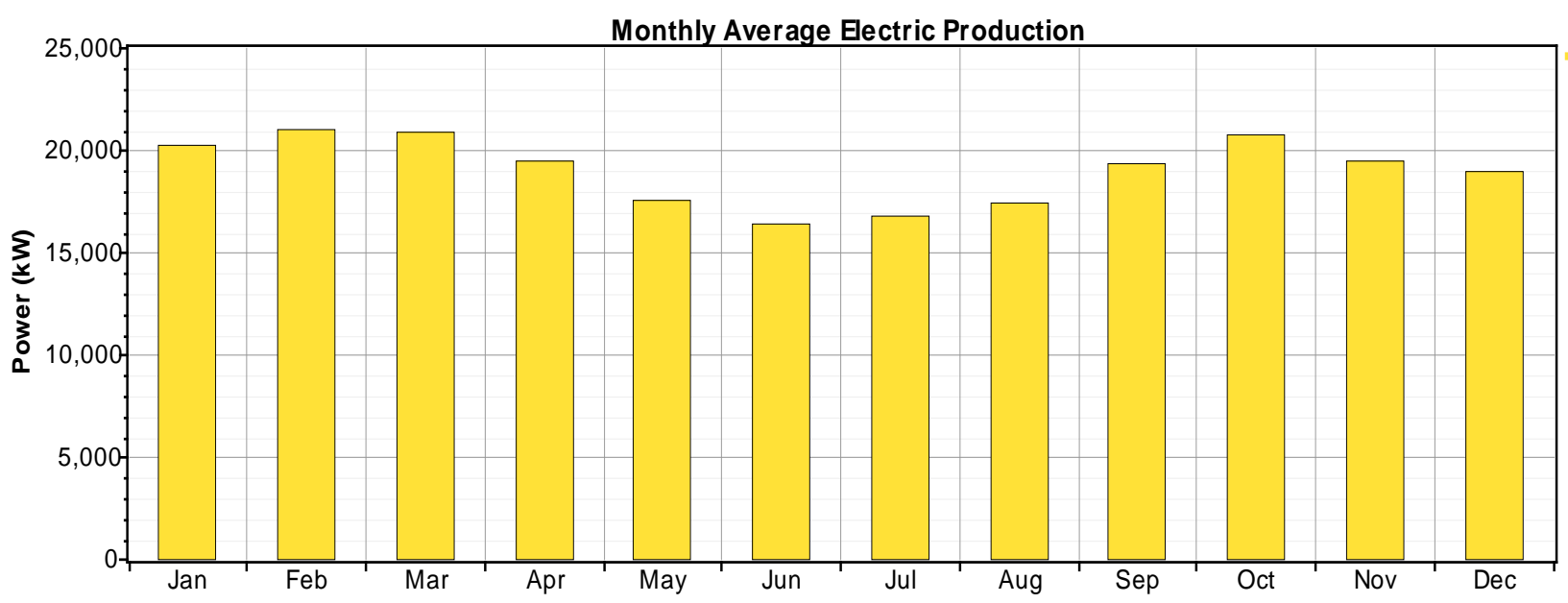

Figure 5. Monthly average PV production.

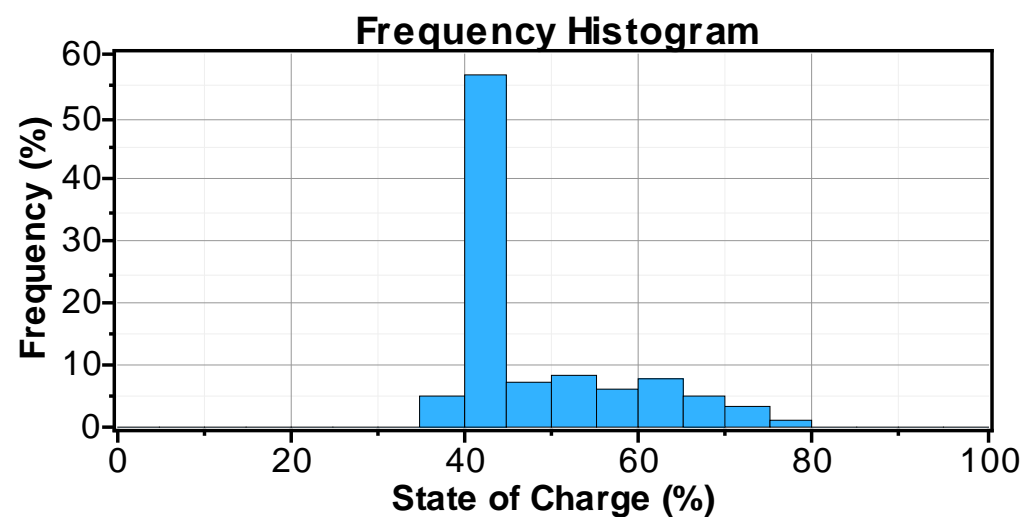

Figure 6. Batteries state of charge. 
The PV only produces electricity at day time. From the simulation results, it is obtained that the excess electricity is about $50.9 \%$ and the unmeet load demand is $52.2 \%$. Demands cannot be fulfilled by the PV without batteries as storage devices. It needs batteries to store the excess electricity from the PV. However the PV/batteries system will need a bulk amount of batteries to store the excess electricity from the PV and fulfill demands at night.

Surrette 6CS25P battery has a maximum capacity of 1,163 Ah. It needs 30,000 batteries to accommodate all excess electricity in order to meet demands in a year. More batteries are needed, if the lifetime of batteries is taken into consideration in the design. The batteries expected lifetime will be decreased as they frequently operate at the low level of their state of charge (SOC). The SOC allowed for the batteries to operate in this design is between $40 \%-100 \%$ as illustrated in Figure 6 to maintain their lifetime for $12 \mathrm{yr}$.

However, another alternative to reduce the big amount of batteries is by combining the PV/battery system with other energy resources (wind, diesel, fuel cell) that can reduce the load on the batteries. It does not only reduce the amount of batteries used, but also maintain the batteries lifetime.

\section{Conclusion}

The HOMER software has simulated and analyzed stand-alone PV energy system based on solar irradiance. The studied energy system includes stand-alone PV system with and without battery storage element. It has been demonstrated that the use PV system with battery can significantly reduce the dependence on solely available diesel resource in Makkah city and western region of Saudi Arabia in general.

\section{Acknowledgements}

The authors thank the Institute of Scientific Research and Revival of Islamic Heritage, Umm Al-Qura University for the research grant.

\section{REFERENCES}

[1] Y. Alyousef, and P. Stevens, The cost of domestic energy prices to Saudi Arabia. Energy Policy, vol. 39, pp. 6900-6905, 2011.

[2] A. S. Yasser, "Renewable energy scenarios for major oil-producing nations: The case of Saudi Arabia,” Futures, vol. 41, pp. 650-662, 2009.

[3] H. A. Saleh, Renewable energy research, development and applications in Saudi Arabia. In: Sayigh, A.A.M. (Ed.), World Renewable Energy Congress VI Pergamon, Oxford, chapt. 345, pp. 1665-1668, 2000.

[4] S. A. Al-Ajlan, A. M. Al-Ibrahim, M. Abdulkhaleq, and F. Alghamdi, Developing sustainable energy policies for electrical energy conservation in Saudi Arabia. Energy Policy, vol. 34, pp. 1556-1565, 2006.

[5] A. Othman, The potential contribution of renewable energy to electricity supply in Saudi Arabia, Energy Policy, vol. 33, pp. 2298-2312, 2005.

[6] O. Alnatheer, The potential contribution of renewable energy to electricity supply in Saudi Arabia, Energy Policy, vol. 33, pp. 2298-2312, 2005.

[7] HOMER HELP, www.homerenergy.com. 